Marquette University

e-Publications@Marquette

Chemistry Faculty Research and Publications

Chemistry, Department of

$1-1-1989$

\title{
A Strategy for the Design of Flame Retardants: Cross-linking Processes
}

Charles A. Wilkie

Marquette University, charles.wilkie@marquette.edu

Sunil J. Sirdesai

Marquette University

Thitivat Suebsaeng

Marquette University

Accepted version. Fire Safety Journal, Vol. 15, No. 4 (1989): 297-311. DOI. (C) 1989 Elsevier B.V. Used with permission. 


\section{Marquette University \\ e-Publications@Marquette}

\section{Chemistry Faculty Research and Publications/College of Arts and Sciences}

This paper is NOT THE PUBLISHED VERSION; but the author's final, peer-reviewed manuscript. The published version may be accessed by following the link in the citation below.

Fire Safety Journal, Vol. 15, No. 4 (1989) : 297-311. DOI. This article is (C) Elsevier and permission has been granted for this version to appear in e-Publications@Marquette. Elsevier does not grant permission for this article to be further copied/distributed or hosted elsewhere without the express permission from Elsevier.

\section{Contents}

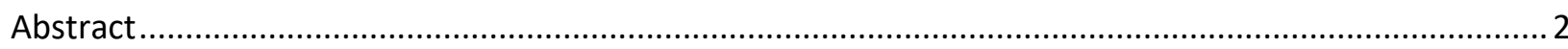

INTRODUCTION

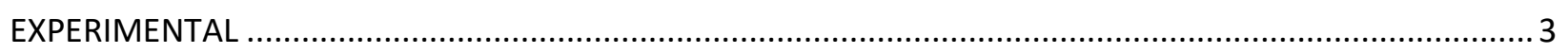

PET reactions---vinyl methylterephthalate and poly(vinyl methylterephthalate) ${ }^{4}$............................... 3

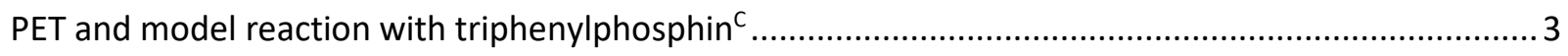

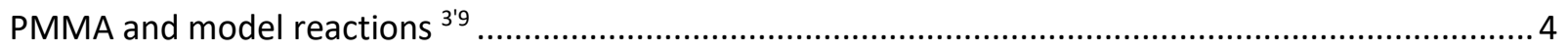

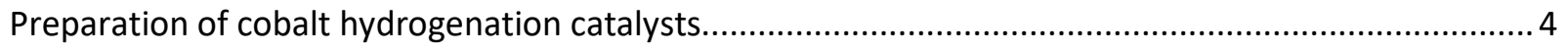

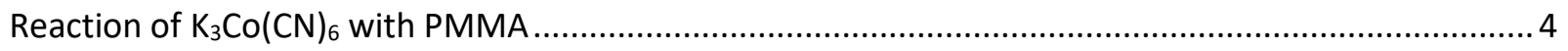

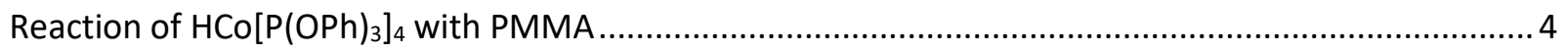

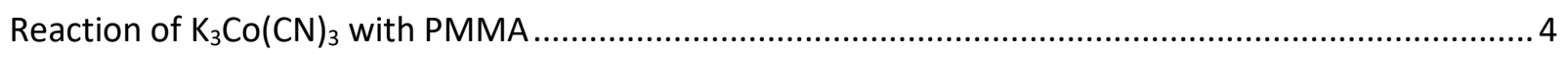

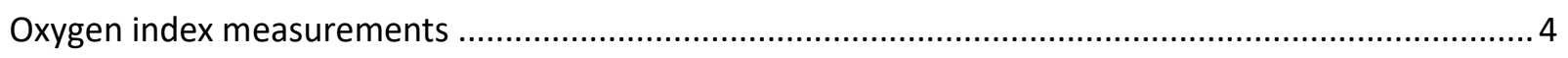

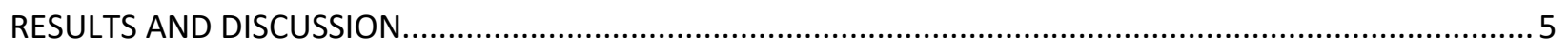

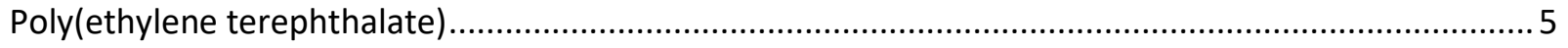

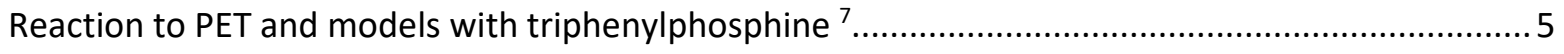

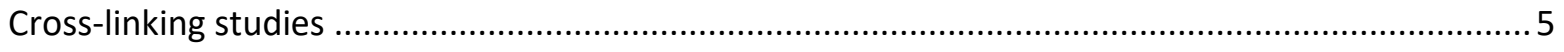

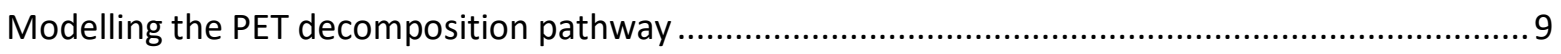

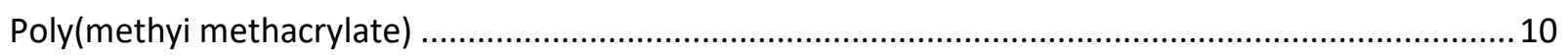




\title{
A Strategy for the Design of Flame Retardants: Cross-Linking Processes
}

\author{
Charles A. Wilkie \\ Department of Chemistry, Marquette University, Milwaukee, WI \\ Sunil J. Sirdesai \\ Department of Chemistry, Marquette University, Milwaukee, WI \\ Thitivat Suebsaeng \\ Department of Chemistry, Marquette University, Milwaukee, WI \\ Po-Hui Chang \\ Department of Chemistry, Marquette University, Milwaukee, WI
}

\begin{abstract}
Cross-linking is identified as an effective means for flame retardation of polymers and schemes for the cross-linking of poly(ethylene terephthalate) and poly(methyl methacrylate) are presented. For poly(ethylene terephthalate) the scheme involves polymerization of the initially produced vinyl ester. This is followed by chain-stripping, producing a polyene, and cyclization of this polyene. For poly(methyl methacrylate) the scheme entails the formation of anhydride linkages between adjacent polymer strands. Evidence is presented to show the efficacy of these processes and information is produced to aid in the identification of new flame retardants.
\end{abstract}

\section{INTRODUCTION}

The process of burning requires that large polymer chains be broken down to give smaller and smaller molecules. Eventually a stage is reached at which the molecules produced have sufficient volatility to escape the surface and enter the gas phase. This scenario indicates that if the combustion of polymers is to be prevented then the breakdown to small molecules must be prevented and instead aggregation of the polymer chains to produce cross-linked polymers made to occur. Van Krevelen ${ }^{1}$ has shown that there is a correlation between char residue and the oxygen index of a polymer; the higher the char, the lower the flammability. Parker et al. $^{2}$ noted that an increase in aromaticity yields high char residues which also correlate with the oxygen index. 
It has been pointed out ${ }^{3}$ that additives to protect polymers from heat and light are developed largely on an empirical basis. The basic understanding of the chemical functions of additives in polymeric systems is frequently unclear. It is necessary to answer several rather fundamental questions about the course of a reaction between additive and polymer and to use that information to design suitable additives for the stabilization of polymers.

In this paper strategies will be considered for the cross-linking of polymer chains to produce intractable chars with greatly increased thermal stability. It will also be shown that the chemistry that occurs between the polymer and the additive is understandable and that the understanding of this chemistry permits the rational design of flame retardants. The polymers that will be discussed are poly(ethylene terephthalate) (PET) and poly(methyl methacrylate) (PMMA). Since each polymer has its own distinct structural features, the strategies that will be developed are quite different.

\section{EXPERIMENTAL}

Chemicals used in this study were obtained from Aldrich Chemical Company, Milwaukee, Wisconsin, USA. ${ }^{1} \mathrm{H}$ NMR spectra were obtained on a Varian EM-360, ${ }^{13} \mathrm{C}$ NMR spectra were obtained on a JEOL-FX-60Q or a GE QE-300. An Analect FX-6200 FT-IR spectrometer was used for infrared spectroscopy and a Hewlett-Packard Model 5980 with a model 5970 mass-selective detector was used for GC-MS. Thermograviteric analysis (TGA) measurements were performed on a Perkin-Elmer TGA-7 instrument. HPLC measurements were obtained using a Waters Instrument.

All reactions were performed in evacuated sealed tubes of about $80 \mathrm{~cm}^{3}$ volume. The typical procedure was to thoroughly evacuate a vessel on a high vacuum line for several hours, then seal the vessel, and place in the muffle furnace preheated to the desired temperature. After two hours the tubes were removed and immediately cooled in liquid nitrogen. Care must be taken in these operations, tubes have been known to explode in the oven and upon removal. Typically, the material was dissolved in a solvent, separated by chromatography, and identified by spectroscopy. Some tubes were equipped with break-seals, which, upon removal from the oven, were resealed to the vacuum line and gasses were quantified by pressure-volume-temperature measurements and identified by IR spectroscopy.

\section{PET reactions---vinyl methylterephthalate and poly(vinyl methylterephthalate $)^{4}$}

Vinyl methylterephthalate $(\mathrm{VMT})^{5}$ and poly(vinyl methylterephthalate) (PVMT) ${ }^{6}$ were synthesized by literature procedures. Pyrolysis reactions were studied in the standard vessels as well as in $5 \mathrm{ml}$ vials in the temperature range from 300 to $400{ }^{\circ} \mathrm{C}$. The small vials were used for quantitation of the methylterephthalate and terephthalic acid that are produced by a silation procedure. After the reaction was complete, the tube was opened and $2.0 \mathrm{ml}$ of a silating solution (Pierce Chemical Company, Rockford, Illinois, USA) and an internal standard (hexadecene) were added. After I $h$ the reaction mixture was injected into a gas chromatograph and the quantity of all materials determined.

\section{PET and model reaction with triphenylphosphin ${ }^{7}$}

Pyrolysis reactions were performed between PET and triphenylphosphine and between methyl myristate, a PET model, and triphenylphosphine in standard vessels in the temperature range 300 to 400 ${ }^{\circ} \mathrm{C}$. 
PMMA and model reactions ${ }^{8,9}$

Typically a 1.0g sample of PMMA was reacted with $0-5 \mathrm{~g}$ of $\mathrm{CIRh}\left(\mathrm{PPh}_{3}\right)_{3}$ at $260^{\circ} \mathrm{C}$ for $2 \mathrm{~h}$.

Reactions with the model compound, dimethyl glutarate (DMG), utilized a 1:1 stoichiometry, $0.17 \mathrm{~g}$

DMG and $1.0 \mathrm{~g} \mathrm{CIRh}\left(\mathrm{PPh}_{3}\right)_{3}$.

\section{Preparation of cobalt hydrogenation catalysts}

$\mathrm{K}_{3} \mathrm{Co}(\mathrm{CN})_{6}$ was prepared following Brauer, ${ }^{10} \mathrm{HCo}\left[\mathrm{P}(\mathrm{OPh})_{3}\right]_{4}$ was prepared following a literature procedure ${ }^{11}$ and $\mathrm{K}_{3} \mathrm{Co}(\mathrm{CN})_{5}$ was prepared following the procedure of Adamson. ${ }^{12}$

\section{Reaction of $\mathrm{K}_{3} \mathrm{Co}(\mathrm{CN})_{6}$ with PMMA}

A 1.0g sample of PMMA and 1.0g of the cobalt compound were combined in standard vessel and pyrolyzed for $2 \mathrm{~h}$ at $375{ }^{\circ} \mathrm{C}$. The tube was removed from the oven and the contents of the tube were observed to be solid (PMMA is liquid at this temperature). The tube was reattached to the vacuum line via the break-seal and opened. Gases were determined by pressure-volume-temperature measurements on the vacuum line and identified by IR spectroscopy. Recovered were $0.22 \mathrm{~g}$ of methyl methacrylate and $0.11 \mathrm{~g}$ of $\mathrm{CO}$ and $\mathrm{CO}_{2}$. The tube was then removed from the vacuum line and acetone was added. Filtration gave two fractions, $1.27 \mathrm{~g}$ of acetone-insoluble material and $0.30 \mathrm{~g}$ of acetone-soluble (some soluble material is always lost in the recovery process). The acetone-insoluble fraction was then slurried with water; $0.11 \mathrm{~g}$ of the material was insoluble in water. Infrared analysis of this insoluble material show both $\mathrm{C}-\mathrm{H}$ and $\mathrm{C}-\mathrm{O}$ vibrations and may be classified as char. Reactions were also performed at lower temperature, but even at $260^{\circ} \mathrm{C}$ some char is evident in the insoluble fraction.

\section{Reaction of $\mathrm{HCO}\left[\mathrm{P}(\mathrm{OPh})_{3}\right]_{4}$ with $\mathrm{PMMA}$}

A 1-0 g sample of PMMA and $1.0 \mathrm{~g}$ of the cobalt compound were combined as above. After pyrolysis at $375^{\circ} \mathrm{C}$ for $2 \mathrm{~h}$ the tube was noted to contain char extending over the length of the tube with a small amount of liquid present. The gases were found to contain $\mathrm{CO}, \mathrm{CO}_{2}$, hydrocarbon (probably methane), and some methyl methacrylate. Upon addition of acetone, 1-0g of soluble material and 0-19g of insoluble may be recovered. The IR spectrum of the insoluble fraction is typical of char.

\section{Reaction of $\mathrm{K}_{3} \mathrm{Co}(\mathrm{CN})_{3}$ with PMMA}

A 1-0 g sample of PMMA and $1.0 \mathrm{~g}$ of $\mathrm{K}_{3} \mathrm{Co}(\mathrm{CN})_{5}$ were combined as above. After pyrolysis for $2 \mathrm{~h}$ at $375^{\circ} \mathrm{C}$ the tube was noted to contain char. The gases consisted of $0-07 \mathrm{~g} \mathrm{CO}, 0.23 \mathrm{~g} \mathrm{CO}_{2}$, and $0.11 \mathrm{~g}$ methyl methacrylate, which were separated by standard vacuum line techniques and identified by IR spectroscopy. The tube was then opened and chloroform and acetone added. The soluble fraction had a mass of $0-36 \mathrm{~g}$, while the insolubles weighed $1.10 \mathrm{~g}$. The insoluble fraction was slurried with water and filtered, giving $0.22 \mathrm{~g}$ of material insoluble in water. The IR spectrum was typical of char.

\section{Oxygen index measurements}

All oxygen index measurements were performed by bottom ignition. The reasons for bottom ignition have been described by Stuetz, ${ }^{13}$ and the present authors have previously reported results from this method. ${ }^{8}$ 


\section{RESULTS AND DISCUSSION}

\section{Poly(ethylene terephthalate)}

\section{Reaction to PET and models with triphenylphosphine ${ }^{7}$}

Triphenylphosphine is known to be a marginally effective flame retardant for PET. ${ }^{14-16}$ In an effort to understand why this is marginally effective, the reaction of triphenylphosphine and PET has been examined. It was reasoned that a knowledge of the reaction pathway will permit a more rational design of a suitable additive for PET. Due to the complexity of the reaction, it was necessary to use a model for PET. Methyl myristate was chosen as the model since its boiling point is in the range used for these pyrolysis reactions. A pathway for the reaction of triphenylphosphine and methyl myristate has been elucidated. ${ }^{7}$ The initial step is the formation of a zwitterionic species which then yields a phosphonium ylide. This ylide attacks a second molecule of zwitterion to ultimately yield methyldiphenylphosphine oxide, ethylene, alkanes, alkenes and other products.

The reaction between triphenylphosphine and PET also produces a phosphine oxide and other products which seem similar to those observed in the methyl myristate-triphenylphosine reaction. The reaction pathway for the triphenylphosphine-PET system is shown in Scheme 1. As above, the initial step is the formation of the zwitterionic species which produces a phosphonium ylide. Attack then produces triphenylphosphine oxide, ethylene, terephthalic acid, and other products. This pathway indicates that all of the flame retardant activity of triphenylphosphine is due to the formation of triphenylphosphine oxide. The literature ${ }^{14}$ notes that triphenylphosphine is not as effective as triphenylphosphine oxide. The reason for the difference, from the above reaction sequence, is the co-production of the volatile, and flammable, ethylene. The efficacy of triphenylphosphine oxide must be due to a gas-phase mechanism. ${ }^{15-16}$

This investigation establishes that the detailed course of the reaction between a polymer and an additive may be determined, especially by the use of model compound studies, and leads to more complex reactions in which it is expected that cross-linking is observed.

\section{Cross-linking studies}

PET offers no pendant groups that may be used for cross-linking reactions. It is thus required that either an additive be provided that will cross-link or that the initial decomposition products be used as this additive. The latter route i.e., the use of the initial decomposition product as the cross-linking agent, has been chosen in this study. 


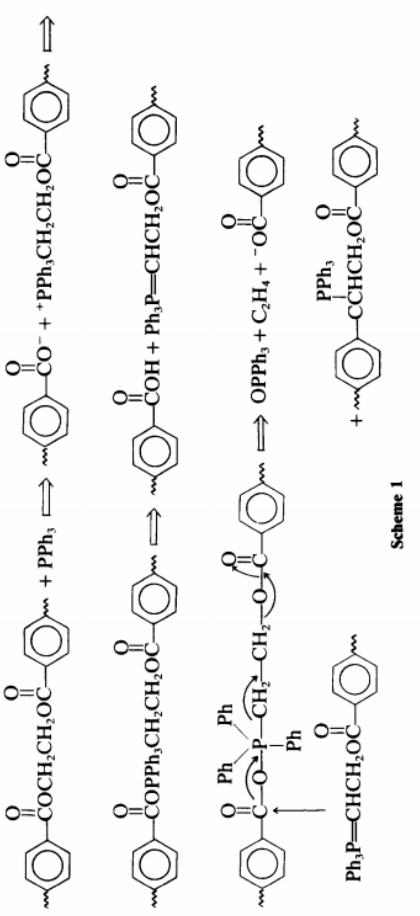

Scheme 1

Many investigators have reported mechanisms for the thermal decomposition of PET, all agree that the initial step is the formation of a vinyl ester and a carboxylic acid via a cyclic transition state.

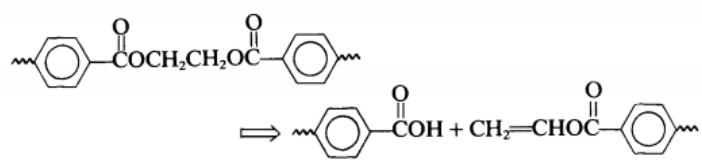

Work by some of the present authors has established, by direct observation, that this is the first step of the reaction. ${ }^{17}$ Zimmermann ${ }^{5}$ and coworkers TM and Yoda et al., ${ }^{6}$ have proposed a mechanism for PET decomposition in which this initially formed vinyl ester undergoes vinyl polymerization followed by chain-stripping. In order to account for the aromatic char that is produced upon PET pyrolysis, it is suggested that these reactions are then followed by cyclization of the polyene produced by chainstripping, similar to that of poly(vinyl chloride). ${ }^{19}$ The reaction of PET with red phosphorus ${ }^{7}$ and with zinc salts ${ }^{20}$ has been investigated and it is found that the results are consistent with this mechanism. The mechanism is delineated in Scheme 2.

This mechanism allows the identification of four steps that must occur for flame retardancy of PET. These are:

(1) PET decomposition must be catalyzed to produce the decomposition at a low temperature. The fate of the PET is determined subsequent to this step. It may undergo further decomposition, which leads to burning, or it may continue to subsequent, cross-linking, steps. There are rigorous temperature requirements for this step. In order to ensure processability, the temperature must be kept as low as possible to negate the possibility of further decomposition. 
(2) The vinyl ester produced in step (1) undergoes vinyl polymerization. This cross-linking step retards further decomposition.

(3) The vinyl polymer produced in step (2) undergoes chainstripping. This generates an unsaturated polymer chain.

(4) The unsaturated polymer chain now cyclizes to produce a polyaromatic char.

The first two steps of this process seem to be the most important. No decomposition should be observed below the processing temperature since this would render processing of the polymer very difficult. On the other hand, the temperature at which the vinyl ester is produced should

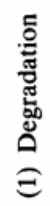

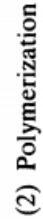
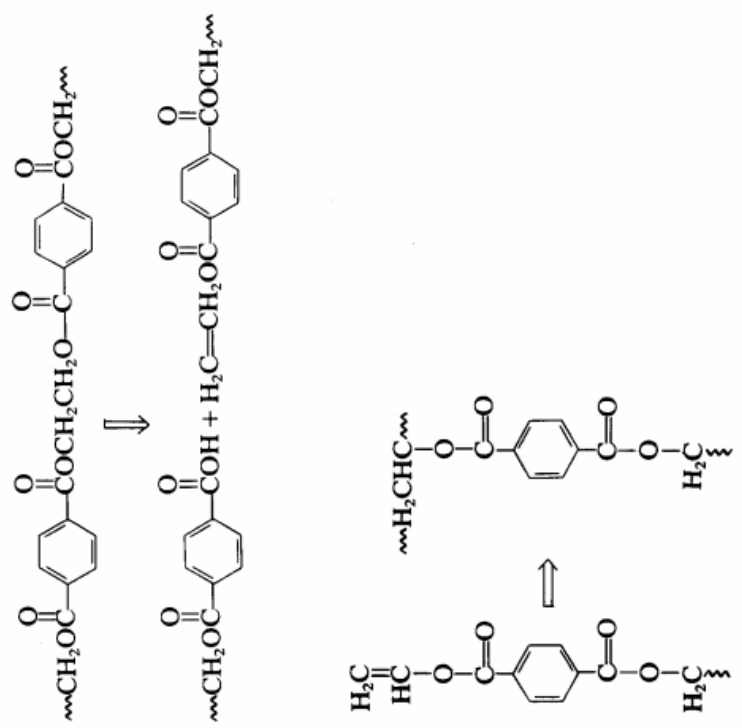


\section{Flame retardants design strategy}

㾞

กำ<smiles>O=C(O[Na])Oc1ccc(C(=O)O)cc1</smiles>

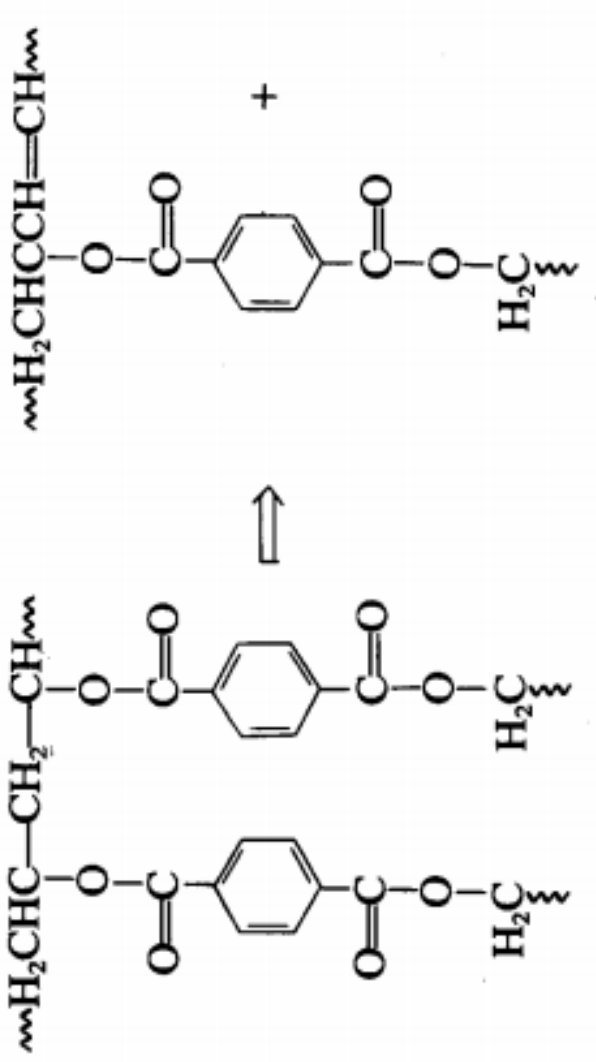

है

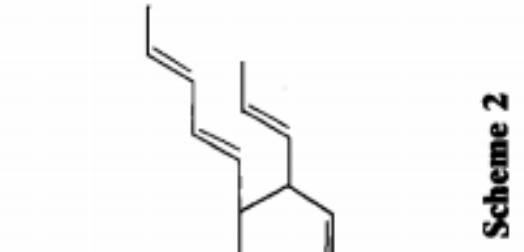


be kept as low as possible since this will minimize the likelihood of further decomposition. This practically means that the reaction should commence at a temperature a little above $300{ }^{\circ} \mathrm{C}$. The second step, the vinyl polymerization, must occur readily almost as soon as the vinyl ester is formed. This will ensure that this species does not readily undergo further decomposition and, instead, is trapped as a crosslinked condensed-phase species. Yoda et al. ${ }^{6}$ report that polymerization, not degradation, of vinyl methylterephthalate occurs at $280^{\circ} \mathrm{C}$. Thus the facile generation of the vinyl ester at a temperature of $280^{\circ}-300^{\circ} \mathrm{C}$ should produce the initially cross-linked polymer.

Modelling the PET decomposition pathway

The pathway that has been presented is an hypothesis, ideally each of the reactions should be studied independently of all others and the course of that reaction delineated. This is likely to be impossible to accomplish for PET. Decomposition of PET alone 17 does not occur until $350{ }^{\circ} \mathrm{C}$, and at $400{ }^{\circ} \mathrm{C}$ an aromatic char is obtained. In the presence of red phosphorus ${ }^{17}$ the' char-producing reactions are accelerated and at $325^{\circ} \mathrm{C}$ the aromatic char is obtained. With $\mathrm{ZnCl}_{2}$ as the additive ${ }^{20}$ this char-forming reaction commences at $300^{\circ} \mathrm{C}$. It is clear that these additives cause acceleration of all of the reactions responsible for char formation and that the individual reactions may not be studied.

It is assumed that the initial reaction is the formation of the vinyl ester and the carboxylic acid, and the latter reactions are examined by the use of vinyl methylterephthalate (VMT) as a PET model. ${ }^{4}$ This monomer may be polymerized at moderate temperature by conventional techniques to give poly(vinyl methylterephthalate) (PVMT) and, at $200{ }^{\circ} \mathrm{C}$ and higher temperatures, PVMT may also be obtained upon pyrolysis of VMT. The thermal formation of the polymer has already been shown by Yoda et al. ${ }^{6}$ Pyrolysis of PVMT produced by either route at $400{ }^{\circ} \mathrm{C}$ produces a char identical to that obtained from pyrolysis of PET at that temperature. Pyrolysis of VMT or PVMT at any temperature between 200 and $400{ }^{\circ} \mathrm{C}$ shows the presence of methylterephthalate as well as dimethylterephthalate and terephthalic acid. The latter two components arise from the disproportionation of the methylterephthalate; this has been demonstrated by the pyrolysis of methylterephthalate alone. At 300 ${ }^{\circ} \mathrm{C}$ absorptions are found in the IR spectrum near $1600 \mathrm{~cm}^{-1}$, attributable to the double bonds formed by chain-stripping, which are lost in the great number of bands observed in this region at higher temperatures and are not seen at lower temperature, since not enough chain-stripping has occurred to give a sufficient number of double bonds. The material produced at $400^{\circ} \mathrm{C}$, unlike that obtained at lower temperature, is completely intractable and identical to that produced by pyrolysis of PET alone. This material is thermally more stable than that produced at lower temperature by TGA analysis and it absorbs about $10 \%$ of the solvent, indicative of cross-linking.

This pathway leads to a clear anomaly: that is, in order to effect flame retardation of PET it is necessary to effect the decomposition of PET at lower temperature. This is contrary to conventional logic which would recommend that decomposition be prevented. In this situation, the cross-linking material must be generated under conditions in which it will not decompose but at a temperature where it will only polymerize. The ideal additive will assist in the cleavage of PET to give the vinyl ester and carboxylic acid so that the vinyl ester may be thermally polymerized rather than further decompose. Work is currently underway to identify such an additive. Following the formation of this vinyl polymer, chain-stripping and polyene cyclization must proceed to give the final aromatic char. The authors think it likely that these reactions will proceed thermally without the requirement of an additive. Work is also underway to test this hypothesis. 
These studies on PET chemistry demonstrate that it is possible to determine the detailed course of a polymeric reaction. More importantly, an understanding of this reaction sequence permits the design of additives that can interfere with the course of the reaction, preventing undesirable reactions, promoting the desired pathway. It must be recognized that this is an iterative process, it is most unlikely that the initial choice will be completely successful; rather it will allow the design of the next additive and the continuation of the process of refinement.

\section{Poly(methyi methacrylate)}

\section{Reactions of PMMA}

The reactions of PMMA with red phosphorus ${ }^{21,22}$ and with Wilkinson's salt, $\mathrm{CIRh}(\mathrm{PPha})_{3},{ }^{23,24}$ have been previously reported by this group. Phosphorus was chosen since this material is known to function as a flame retardant for oxygenated polymers. ${ }^{23}$ The reaction with phosphorus identifies the carbonyl as the site of reactivity in PMMA; Wilkinson's salt was accordingly chosen, since it is well known that it reacts with carbonyls. ${ }^{24}$ The reaction between the rhodium compound and PMMA is observed to produce significant amounts of insoluble matter, char, and this char contains anhydrides. The oxygen index, bottom ignition, ${ }^{13}$ increases from about 14 for pure PMMA to about 20 for $10 \%$ rhodium compound in PMMA. TGA analysis indicates that about $25 \%$ of the sample is non-volatile at $600^{\circ} \mathrm{C}$ and the glass transition temperature increases by about $15^{\circ} \mathrm{C}$ by Differential Scanning Calorimetry (DSC).

In order to understand this reaction, DMG was used as a PMMA model. Six different rhodium compounds were isolated and identified from this reaction and could be seen to arise from an oxidative insertion into a carbon-oxygen bond followed by ligand exchange reactions.

It is believed that a similar reaction occurs between $\mathrm{PMMA}$ and $\mathrm{CIRh}\left(\mathrm{PPh}_{3}\right)_{3}$. A summary of the reaction is presented in Scheme 3. The initial step is an oxidative addition of $\mathrm{RhCl}\left(\mathrm{PPh}_{3}\right)_{3}$ to one of the C$\mathrm{O}$ bonds of the ester moiety and produces rhodium-carbon and rhodiumoxygen bonds. Adjacent rhodium species can undergo further reaction with the formation of anhydride linkages. This anhydride formation may occur between adjacent pairs of reactants, between pairs in the 

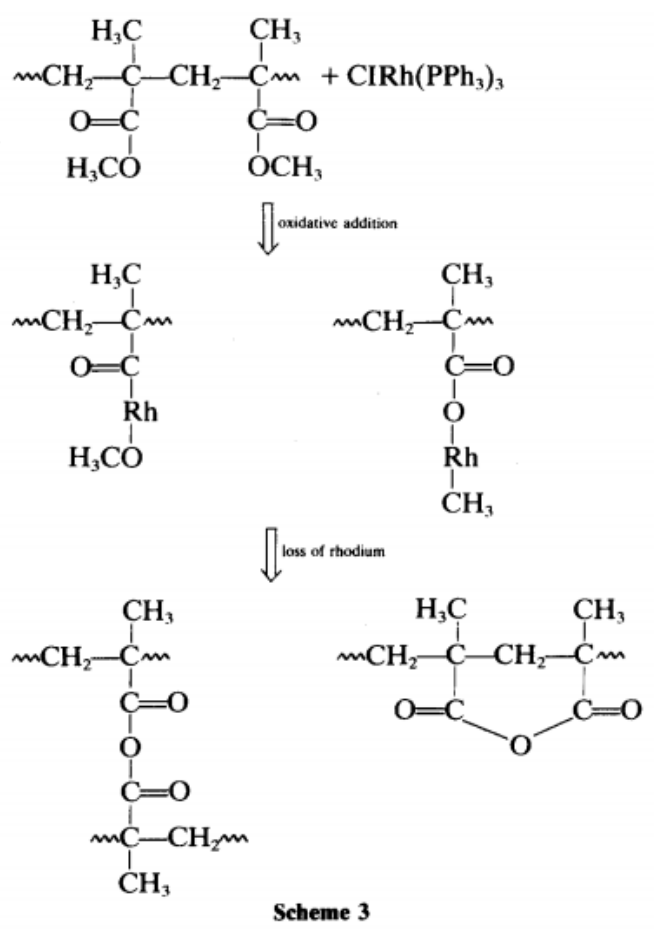

same chain or between pairs that are present in different chains. All of these reactions are observed. However, the last reaction is the one of interest here, since this leads to cross-linking and ultimately to char formation. Rhodium is present in both the charred material and in the soluble fractions. From the reaction pathway in order for rhodium elimination to occur, two rhodium-inserted moieties must be proximate. Since this cannot always occur, rhodium must be present both in the char as well as in the soluble fraction.

It is unlikely that $\mathrm{CIRh}\left(\mathrm{PPh}_{3}\right)_{3}$ will ever be useful as a flame retardant due to its red color, expense and the potential toxicity associated with a heavy metal. This discovery is nonetheless important because it allows delineation of a set of requirements for flame retardants that function by this mechanism. These requirements are:

(1) The compound must be able to effectively bind to carbonyl; thus it must be a transition metal compound.

(2) The compound must be capable of undergoing oxidative addition to the carbonyl.

(3) It should be coordinatively unsaturated. This is a corollary of (2).

(4) Since Wilkinson's salt is a catalyst for a variety of reactions, a compound known to have catalytic activity may be desirable. This is a corollary of (3).

(5) The compound should be colorless and inexpensive.

The authors believe that this set of requirements provide an excellent guide to the elucidation of compounds that will function as flame retardants for PMMA. Since Wilkinson's salt is best known as a hydrogenation catalyst and since a hydrogenation catalyst must possess all of the characteristics identified above, it seems reasonable to suggest that transition metal compounds that are known to 
function as hydrogenation catalysts may be useful flame retardants additives for PMMA. Three compounds have been selected for further investigation: potassium cyanocobaltate(III), $\mathrm{KaCo}(\mathrm{CN})_{6}$, potassium cyanocobaltate(II), $\mathrm{KaCo}(\mathrm{CN})_{5}$, and tetrakis(triphenylphosphite)hydridocobalt, $\mathrm{HCO}\left[\mathrm{P}(\mathrm{OPh})_{3}\right]_{4}$. The cobalt(II) compound has been shown to function as a hydrogenation catalyst 25,26 and the cobalt(III) compound is related to this. The phosphine complex is related to a compound that has been shown to have catalytic activity, $\mathrm{CaHsCo}\left[\mathrm{P}(\mathrm{OMe})_{3}\right]_{4} \cdot{ }^{27}$ The authors have found that the oxygen index increases by about 5 points, from 14 for neat PMMA to about 19 for all three of these compounds, $\mathrm{KaCo}(\mathrm{CN})_{5}, \mathrm{~K}_{3} \mathrm{Co}(\mathrm{CN})_{6}$, and $\mathrm{HCO}\left[\mathrm{P}(\mathrm{OPh})_{3}\right]_{4}$. In addition, char formation and reduced monomer production are observed for all of these additives upon reaction with PMMA. Ideally, it would be hoped that no monomer formation and complete char production are observed. Such is not the case here; therefore these materials probably have no utility as flame retardant additives for PMMA, since monomer formation, even at a reduced level, will still permit a propagation of the burning process. The authors take this to be a starting point in the search for suitable additives. While somewhat positive results for these three additives do not prove the validity of the hypothesis, these results do indicate that further investigations are warranted. Further work is underway to refine the hypothesis and to identify other potential hydrogenation catalysts that may prove useful as flame retardants for PMMA.

It should be noted that other schemes for the production of anhydrides are also possible. It should also be noted that anhydride formation is not the only means of cross-linking PMMA chains; other schemes for cross-linking are also under investigation.

\section{CONCLUSION}

In this paper evidence has been presented to show that it is quite feasible to determine the detailed course of reaction between a polymer and an additive. Further, the understanding of this reaction pathway provides insight into new additives and schemes for the identification of efficacious flame retardant additives. Finally, schemes have been elucidated for the cross-linking of both PET and PMMA and the schemes have been shown to provide a route for flame retardation of these polymers. It is imperative to realize that the purpose of this work is not to directly develop new flame retardants, rather the purpose is to expose the chemistry that occurs when a polymer and an additive react. This exposition of chemistry continually provides a new starting point for further investigations. The more that pathways for polymeric reactions are determined the more information is available to design suitable additives to prevent degradation of polymers.

\section{ACKNOWLEDGEMENT}

The support of the Center for Fire Research at the National Institute of Standards and Technology under Grant Number 60NANB6D0602 is gratefully acknowledged.

\section{REFERENCES}

1. Van Krevelen, D. W., Polymer, 16 (1975) 615.

2. Parker, J. A., Fohlen, G. M. \& Sawko, P. M., cited in Pearce, E. M., Khana, Y. P. \& Raucher, D., In Thermal Characterization of Polymeric Materials, ed. E. A. Turi. Academic Press, NY, p. 807.

3. Starnes, W. H. Jr., In Developments in Polymer Degradation, Vol. 3, ed. N. Grassie. Applied Science, London, 1981, p. 135.

4. Chang, Po-Hui \& Wilkie, C. A. J. Appl. Polym. Sci., in press. 
5. Zimmermann, H., Faserforsch. Textiltech., 17 (1966) 228.

6. Yoda, K., Tsuboi, A., Wada, M. \& Yamadera, R., J. Appl. Polym. Sci., 14 (1970) 2357.

7. Suebsaeng, T., Wilkie, C. A. \& Brown, C. E., J. Polym. Sci., Polym. Chem. Edn., 26 (1988) 2705.

8. Sirdesai, S. \& Wilkie, C. A., J. Appl. Polym. Sci., 37 (1989) 863.

9. Sirdesai, S. \& Wilkie, C. A., J. Appl. Polym. Sci., 37 (1989) 1595.

10. Brauer, G., Handbook of Preparative Inorganic Chemistry. Academic Press, NY, 1965, p. 1541.

11. Levison, J. J. \& Robinson, S. D., Inorganic Synthesis, 13 (1972) 105.

12. Adamson, A. W., J. Am. Chem. Soc., 73 (1951) 5710.

13. Stuetz, D. E., Diedwardo, A. H., Zitomer, F. \& Barnes, B. P., J. Polym. Sci., Polym. Chem. Edn., 13 (1973)585.

14. Einsele, U., Weber, N. \& Herlenger, H., Textilveredlung., 14 (1972) 192.

15. Hastie, J. W., J. Res. Nat. Bur. Stand., 77a (1973) 733.

16. Hastie, J. W. \& McBee, C. L., Mechanistic study of triphenylphosphine oxide---poly(ethyelen terephthalate) and related flame retardant systems. Report NBSIR 75-741, National Bureau of Standards, Washington, DC, 1975.

17. Suebsaeng, T., Wilkie, C. A., Burger, V. T., Carter, J. \& Brown, C. E., J. Polym. Sci., Polym. Chem. Edn., 22 (1984) 945.

18. Zimmermann, H. \& Leibnitz, E., Faserforsch. Textiltech., 16 (1965) 282.

19. Lattimer, R. P. \& Kroenke, W. J., J. Appl. Polym. Sci., 25 (1980) 101.

20. Suebsaeng, T., Wilkie, C. A., Burger, V. T., Carter, J. \& Brown, C. E., J. Polym. Sci., Polym. Lett. Edn., 22 (1984) 625.

21. Wilkie, C. A., Pettegrew, J. W. \& Brown, C. E., J. Polym. Sci., Polym. Lett. Edn., 19 (1981), 409.

22. Brown, C. E., Wilkie, C. A., Smukalla, J., Cody, tC B., Jr. \& Kinsinger, J. A., J. Polym. Sci., Polym. Chem. Edn., 24 (1986) 1297.

23. Peters, E. N., Flame Retardancy of Polymeric Materials, 5 (1979) 113.

24. Tsuji, J., In Organic Synthesis via Metal Carbonyls. Wiley-Interscience, NY, 1977, p. 595.

25. Kwiatek, J., Mador, I. L. \& Seyler, J. K., J. Am. Chem. Soc., 84 (1962) 304.

26. King, N. K. \& Winfield, M. E., J. Am. Chem. Soc., 83 (1961) 3366.

27. Bleeke, J. R. \& Muetterties, E. L., J. Am. Chem. Soc., 103 (1981) 556. 